\title{
CD20 expression sub-stratifies standard-risk patients with B cell precursor acute Iymphoblastic leukemia
}

\author{
Shen Miao Yang ${ }^{1}$, Jing Wang ${ }^{1}$, Ting Zhao ${ }^{1}$, JinSong Jia ${ }^{1}$, HongHu Zhu ${ }^{1}$, Hao Jiang ${ }^{1}$, \\ Jin Lu ${ }^{1}$, Bin Jiang ${ }^{1}$, HongXia Shi ${ }^{1}$, YanRong Liu ${ }^{1}$, YueYun Lai ${ }^{1}$, LanPing Xu ${ }^{1}$, XiaoJun \\ Huang $^{1,2}$ and Qian Jiang ${ }^{1}$ \\ ${ }^{1}$ Peking University People's Hospital, Peking University Institute of Hematology, Beijing, China \\ ${ }^{2}$ Peking Tsinghua Center for Life Sciences, Academy for Advanced Interdisciplinary Studies, Peking University, Beijing, China \\ Correspondence to: Qian Jiang, email: jiangqian@medmail.com.cn \\ Keywords: CD20; adult; Ph-negative; B cell precursor acute lymphoblastic leukemia \\ Received: June 12, $2017 \quad$ Accepted: September 08, $2017 \quad$ Published: October 31, 2017 \\ Copyright: Yang et al. This is an open-access article distributed under the terms of the Creative Commons Attribution License 3.0 \\ (CC BY 3.0), which permits unrestricted use, distribution, and reproduction in any medium, provided the original author and source \\ are credited.
}

\section{ABSTRACT}

Patients with standard-risk adult acute lymphoblastic leukemia (ALL) treated with chemotherapy do not have satisfactory outcomes. To more precisely classify ALL patients and optimize treatment, we re-evaluated the risk stratification system by examining CD20 expression and other classic risk factors at diagnosis. We retrospectively analyzed response to induction chemotherapy of 217 consecutive patients with newly diagnosed Philadelphia-negative B cell precursor-ALL. Survival analyses were conducted for the 136 patients who were intended to be treated with chemotherapy alone. Among the 217 patients, $69(31.8 \%)$ were considered standard risk based on age $<35$ years, white blood cell count $<30 \times 10^{9} / \mathrm{L}$, absence of central nervous system involvement, and high-risk cytogenetic abnormalities. Seventy-four patients ( $34.1 \%$ ) expressed CD20 on $\geq 20 \%$ of leukemia blasts and were considered CD20 positive. We found that fewer CD20-positive than CD20negative patients achieved durable first complete responses (CR1 $\geq 3$ months) (81.1\% vs. $94.9 \%, P=0.002)$. Within the standard-risk group, more CD20-negative than CD20-positive patients achieved CR (100\% vs. $83.3 \%, P=0.003)$ and durable CR1 (100\% vs. 82.4\%, $P=0.014)$. For patients in the CD20-negative standard-risk, CD20-positive standard-risk, CD20-negative high-risk, and CD20-positive high-risk groups, the 3-year cumulative incidence of relapse was $42.6 \%, 70.0 \%, 59.3 \%$, and $69.5 \%$, respectively $(P=0.118)$; the 3 -year disease-free survival rates were $52.1 \%$, $0 \%, 20.7 \%$, and $13.7 \%$, respectively $(P=0.006)$; and the 3 -year overall survival rates were $55.8 \%, 13.8 \%, 23.6 \%$, and $16.9 \%$, respectively $(P=0.006)$. Our results suggest that patients with CD20-negative standard-risk B cell precursor-ALL have favorable prognosis compared with CD20-positive standard-risk or CD20-negative or -positive high-risk patients. CD20-positive standard-risk ALL patients may need other therapeutic modalities bridging to allogeneic hematopoietic stem cell transplantation.

\section{INTRODUCTION}

Patients with acute lymphoblastic leukemia (ALL) are currently treated with risk-adapted therapeutic strategies and molecularly targeted agents. Classic risk factors for adult patients with ALL at diagnosis include older age [1-3], high white blood cell (WBC) count [3, 4], specific cytogenetic abnormalities [5, 6], and central nervous system (CNS) involvement [7]. Response to induction chemotherapy [4] and minimal residual disease monitored during chemotherapies have also been demonstrated to be significant prognostic factors 
$[8,9]$. For high-risk patients, allogeneic hematopoietic stem cell transplantation (allo-HCT) is accepted as a curative option. However, the 10-year overall survival (OS) rate of patients without high-risk characteristics treated with chemotherapy alone is only $38.9 \%$ [10]. This unsatisfactory outcome has prompted some investigators to treat standard-risk patients with allo-HCT at first complete response (CR1) [11-14]. Our experience suggests that standard-risk population is heterogeneous, necessitating the identification of patients who could be spared intensive treatment such as allo-HCT. To this end, we evaluated CD20 expression on leukemic cells, which is a known independent adverse prognostic marker for ALL patients $[15,16]$ together with the classic risk stratification system for patients with Philadelphia-negative B cell precursor (BCP)-ALL.

\section{RESULTS}

\section{Patient characteristics}

Among the 217 patients evaluated, 111 were male and 106 were female. The median age was 34 years with a range of 18-64 years. Sixty-nine patients $(31.8 \%)$ were at standard risk. Seventy-four patients (34.1\%) expressed CD20 on ALL cells and were considered CD20-positive. The proportion of CD20-positive patients was not significantly different between the high-risk (37.8\%) and low-risk groups $(26.1 \%, \mathrm{P}=0.089)$.

CD20 expression was not associated with classic high-risk factors, including age $\geq 35$ years, WBC $\geq 30$ $\times 10^{9} / \mathrm{L}$ at diagnosis, CNS involvement, and cytogenetic risk. Platelet counts were lower in the $\mathrm{CD} 20$-positive than in the $\mathrm{CD} 20$-negative group $(\mathrm{P}=0.006)$. More $\mathrm{CD} 20$-positive than CD20-negative patients had extramedullary disease (EMD) $(50.6 \%$ vs $28.1 \%, \mathrm{P}=0.001)$, hepatosplenomegaly and lymphadenopathy ( $41.6 \%$ vs $26.3 \%, \mathrm{P}=0.006)$, and CNS involvement ( $10.4 \%$ vs $1.9 \%, \mathrm{P}=0.006)$ (Table 1$)$.

\section{Response}

Complete response (CR) was achieved with the first course of induction chemotherapy (defined as CRearly) in 176 patients $(81.1 \%)$, and after one or more courses of chemotherapy (CRfinal) in 205 patients $(94.5 \%)$. We defined durable $\mathrm{CR} 1$ as $\mathrm{CR} \geq 3$ months representing a reasonable time period to prepare for allo-HCT. Of the 217 patients, 195 (89.9\%) achieved durable CR1.

The CD20-positive and CD20-negative groups did not differ in the proportion of patients achieving CRearly ( $81.8 \%$ vs. $79.7 \%$, respectively; $\mathrm{P}=0.709$ ) or CRfinal ( $96.5 \%$ vs. $90.5 \%$, respectively; $\mathrm{P}=0.113$ ). However, fewer CD20-positive than CD20-negative patients achieved durable CR1 ( $81.1 \%$ vs. $94.9 \%, \mathrm{P}=0.002)$.

When analyzed according to risk status, the standard-risk and high-risk patients did not differ in the proportion achieving CRearly $(84.1 \%$ vs $79.7 \%$, respectively; $\mathrm{P}=0.448)$, CRfinal $(95.7 \%$ vs. $93.9 \%$, respectively; $\mathrm{P}=0.756)$, or durable $\mathrm{CR} 1$ ( $95.5 \%$ vs $91.9 \%$, respectively; $\mathrm{P}=0.123$ ). However, within the standardrisk group, more $\mathrm{CD} 20$-negative than $\mathrm{CD} 20$-positive patients achieved CRfinal (100\% vs. $83.3 \%$, respectively; $\mathrm{P}=0.003)$ and durable $\mathrm{CR} 1(100 \%$ vs. $82.4 \%$, respectively; $\mathrm{P}=0.014)$. The CD20-negative and CD20-positive standard-risk patients did not differ in the rate of CRearly ( $88.2 \%$ vs. $72.4 \%$, respectively; $\mathrm{P}=0.140$ ). In the highrisk group, there were no differences in $\mathrm{CR}$ rates between CD20-positive and CD20-negative patients (Table 2).

\section{Long-term outcomes}

Of the 217 BCP-ALL patients, 81 patients received allo-HCT in CR1. The outcomes of those patients are not discussed here. The remaining 136 were intended to be treated with chemotherapy alone. Within this subset, platelet counts were lower and extramedullary disease (EMD) was more common in the CD20-positive patients than in CD20-negative patients. However, the proportion of patients with hepatosplenomegaly and CNS leukemia (CNSL) was not significantly different between the two groups (Table 3). And the proportion of patients treated with consolidation regimens of hyperCVAD after CR1 was not significantly different. The median follow-up was 33.0 (range 10.0-170.0) months. The 3-year cumulative incidence of relapse (CIR) was $64.4 \%$, of non-relapse mortality was $14.3 \%$, of disease-free survival (DFS) was $21.0 \%$, and of OS was $25.3 \%$.

We used univariate analysis to evaluate the prognostic significance of the clinical characteristics included in the risk stratifications as well as sex, hemoglobin level, platelet count, CD20 expression, lymphadenopathy, hepatosplenomegaly, and consolidation regimen. High-risk patients had lower 3-year OS than standard-risk patients $(25.9 \%$ vs. $53.6 \%$, respectively; $\mathrm{P}=0.007)$. CD20-positive patients had higher 3-year CIR than CD20-negative patients $(73.1 \%$ vs. $54.7 \%$, respectively; $\mathrm{P}=0.015)$ and lower 3-year DFS $(12.2 \%$ vs. $29.7 \%$, respectively; $\mathrm{P}=0.013$ ) (Figure 1 ). We performed multivariate analysis of factors with a $\mathrm{P}$ value $<0.20$ in the univariate analysis (Table 3). High-risk score was the only independent adverse factor for OS (hazard ratio [HR] 2.055, 95\% confidence intervals [CI] 1.199-3.527, $\mathrm{P}=0.009$ ), and $\mathrm{CD} 20$ expression was the only independent adverse factor for DFS (HR 1.917, 95\% CI 1.237-2.971, $\mathrm{P}=0.004$ ) and CIR (HR 1.802, 95\% CI 1.061-3.061, $\mathrm{P}=0.029$ ) (Table 4).

We next analyzed the outcome of groups combining risk status and CD20 expression. We found that CD20negative standard-risk patients had a significantly better DFS and OS than did the CD20-positive standard-risk, CD20-positive high-risk, and CD20-negative high-risk patients. Survival did not differ among the latter three 
Table 1: Patient characteristics

\begin{tabular}{|c|c|c|c|}
\hline & CD20 positive $n=74$ & CD20 negative $n=143$ & $\mathbf{P}$ \\
\hline $\operatorname{Sex}(M / F)$ & $39 / 35$ & $72 / 71$ & 0.742 \\
\hline Age (median, range) & $37.0(18-64)$ & $33.0(18-61)$ & 0.486 \\
\hline WBC (median, range) & $8.72(1.0-379.37)$ & $8.97(1.09-563.57)$ & 0.447 \\
\hline HB (median, range) & $92.0(51.0-152.0)$ & $85.5(38.0-158.0)$ & $0.027^{*}$ \\
\hline PLT (median, range) & $41.5(3.0-285.0)$ & $67(5.0-391.5)$ & $0.014^{*}$ \\
\hline $\operatorname{EMD}(\mathrm{n},(\%))$ & $39(52.7)$ & $38(26.6)$ & $<0.001^{* *}$ \\
\hline $\begin{array}{l}\text { Hepatosplenomegaly and } \\
\text { lymphadeopathy }(\mathrm{n},(\%))\end{array}$ & $32(43.2)$ & $35(24.5)$ & $0.005^{* *}$ \\
\hline CNSL $(\mathrm{n},(\%))$ & $8(10.8)$ & $3(2.1)$ & $0.009^{* *}$ \\
\hline Cytogenetic risk $(\mathrm{n},(\%))$ & & & 0.486 \\
\hline Low & $1(1.4)$ & $2(1.4)$ & \\
\hline Intermediate & $44(59.5)$ & $94(65.7)$ & \\
\hline High and very high & $29(39.2)$ & $47(32.9)$ & \\
\hline $\begin{array}{l}\text { 11q23/MLL } \\
\text { translocations }\end{array}$ & 0 & 13 & \\
\hline $\mathrm{t}(1 ; 19)$ & 2 & 5 & \\
\hline Complex karyotype & 8 & 9 & \\
\hline$-7, \operatorname{del}(7)$ & 6 & 7 & \\
\hline+8 & 4 & 6 & \\
\hline $\begin{array}{l}\text { low hypodiploidy } \\
(30-39)\end{array}$ & 9 & 7 & \\
\hline Risk stratification & & & 0.089 \\
\hline Standard risk & $18(24.3)$ & $51(35.7)$ & \\
\hline High risk & $56(75.7)$ & $92(64.3)$ & \\
\hline
\end{tabular}

Table 2: Patient response according to risk status and CD20 expression

\begin{tabular}{|c|c|c|c|c|c|c|c|}
\hline & \multicolumn{3}{|c|}{ Standard risk } & \multicolumn{3}{|c|}{ High risk } & \multirow[b]{2}{*}{$\mathbf{P}$} \\
\hline & $\begin{array}{c}\text { CD20- } \\
\text { negative }\end{array}$ & $\begin{array}{l}\text { CD20- } \\
\text { positive }\end{array}$ & $\mathbf{P}$ & $\begin{array}{c}\text { CD20- } \\
\text { negative }\end{array}$ & CD20-positive & $\mathbf{P}$ & \\
\hline durable $\mathrm{CR} 1 \geq 3$ months & $100 \%$ & $82.4 \%$ & $0.014^{*}$ & $92.4 \%$ & $85.2 \%$ & 0.166 & 0.123 \\
\hline $\begin{array}{l}\text { CR after the first course } \\
\text { of chemotherapy } \\
\text { (CRearly) }\end{array}$ & $88.2 \%$ & $72.2 \%$ & 0.140 & $78.3 \%$ & $82.1 \%$ & 0.569 & 0.448 \\
\hline $\begin{array}{l}\text { CR after any } \\
\text { course of induction } \\
\text { chemotherapies(CRfinal) }\end{array}$ & $100 \%$ & $83.3 \%$ & $0.003^{* *}$ & $94.6 \%$ & $92.9 \%$ & 0.730 & $0.030^{*}$ \\
\hline
\end{tabular}


Table 3: Characteristics of patients intended to be treated with chemotherapy

\begin{tabular}{lccc}
\hline & CD20 positive $\mathbf{n}=\mathbf{5 5}$ & CD20 negative $\mathbf{n = 8 1}$ & P \\
\hline Sex (M/F) & $27 / 28$ & $41 / 40$ & 0.861 \\
Age (median, range) & $37.0(18-64)$ & $35.0(18-61)$ & 0.401 \\
WBC (median, range) & $10.85(1.58-379.37)$ & $8.66(1.2-563.57)$ & 0.928 \\
HB (median, range) & $92.0(39.2-152.0)$ & $85.5(38.0-154.0)$ & 0.193 \\
PLT (median, range) & $34.5(6.0-272.0)$ & $58.0(7.0-391.5)$ & $0.029^{*}$ \\
EMD (n, (\%)) & $31(56.3)$ & $26(32.1)$ & $0.005^{* *}$ \\
$\quad$ Hepatosplenomegaly and & $26(47.3)$ & $25(30.9)$ & 0.052 \\
$\quad$ lymphadeopathy (n, (\%)) & $6(10.9)$ & $3(3.7)$ & 0.157 \\
$\quad$ CNSL (n, (\%)) & $1(1.8)$ & & 0.123 \\
Cytogenetic risk (n, (\%)) & $42(76.4)$ & $58(71.6)$ & \\
$\quad$ Low & $12(21.8)$ & $23(28.4)$ & 0.765 \\
Intermediate & & & \\
$\quad$ High and very high & $15(27.3)$ & $24(29.6)$ & 0.500 \\
Risk stratification & $40(72.7)$ & $57(70.4)$ & \\
$\quad$ Standard risk & $15(27.3)$ & $63(77.8)$ & \\
$\quad$ High risk & $40(72.7)$ & & \\
Consolidation regimen & & & \\
$\quad$ HyperCVAD & Non-hyperCVAD & & \\
\hline
\end{tabular}

groups. The CD20-negative standard-risk, CD20-positive standard-risk, CD20-negative high-risk, and CD20positive high-risk patients had 3-year CIR rates of $42.6 \%$, $70.0 \%, 59.3 \%$, and $69.5 \%$, respectively $(\mathrm{P}=0.118)$; 3 -year DFS rates of $52.1 \%, 0 \%, 20.7 \%$, and $13.7 \%$, respectively $(\mathrm{P}=0.006)$; and 3 -year OS rates of $55.8 \%, 13.8 \%, 23.6 \%$, and $16.9 \%$, respectively $(\mathrm{P}=0.006)$ (Figure 1$)$.

\section{DISCUSSION}

With this study, we describe that CD20 expression can be helpful in understanding characteristics of standardrisk BCP-ALL patients. CD20-negative patients with standard-risk BCP-ALL had the most favorable outcomes, while the prognosis for CD20-positive standard-risk patients was poor, similar to that of high-risk patients.

Furthermore, CD20 expression was the only independent risk factor for poor DFS in patients treated with conventional chemotherapy alone. This adverse prognostic significance of CD20 expression for survival is consistent with the results of other studies. Thomas et al. reported that the 3-year rates of durable CR and OS were uniformly poor for the CD20-positive group as compared with the CD20-negative group, regardless of the chemotherapy regimen (durable CR $20 \%$ vs $55 \%$,
$\mathrm{P}<0.001$; OS $27 \%$ vs $40 \%, \mathrm{P}=0.03$, respectively) [15]. The phase II study of the Group for Research on Adult Acute Lymphoblastic Leukemia (GRAALL), conducted in patients with Philadelphia ( $\mathrm{Ph}$ )-negative ALL, found CD20 expression to be independently associated with higher CIR $(\mathrm{HR}=1.9, \mathrm{P}=0.045)$ [16].

CD20 is expressed on both normal and malignant B cells. CD20 is a $33-37 \mathrm{kDa}$ nonglycosylated transmembrane phosphoprotein that forms tetramers and functions in store-operated calcium entry [17]. Studies with small interfering RNA-mediated knockdown of CD20 expression or monoclonal antibody-mediated blocking of CD20 function have shown that this molecule plays an important role in cell-cycle progression and differentiation via downstream signaling pathways. Downregulation of CD20 expression in Ramos cells results in an increase in apoptosis [18]. Rituximab (antiCD20) treatment preferentially inhibits expression of the antiapoptotic proteins $\mathrm{Bcl}-2 / \mathrm{Bcl}-\mathrm{xL}$ via constitutive activation of p38 MAPK, ERK 1/2, NF-кB, and AKT pathways [19]. These molecular studies may explain the pathophysiological and prognostic significance of CD20 expression.

We found that CD20 expression was associated with lower platelet counts and higher rates of EMD, 
especially CNSL, the latter being a well-accepted poor risk factor. In addition to some of the patient characteristics at diagnosis, their treatment responses were strong indicators of outcome. The low rate of durable CR1 observed in patients with ALL suggests an unsatisfying depth of response, which is also associated with poor outcome.

In previous studies, classic risk factors, such as age $\geq 35$ years, WBC count $\geq 30 \times 10^{9} / \mathrm{L}, \mathrm{CNSL}$, and highrisk chromosomal abnormalities, did not seem to affect the response rates of patients with $\mathrm{BCP}-\mathrm{ALL}[15,16]$. This is consistent with our inability to detect a significant difference in the response rates between standard- and high-risk groups.

In the 217 patients evaluated here, 31.8\% were at standard risk and $34.1 \%$ were CD20 positive, which is in line with the frequencies in other studies [15, 16, $20,21]$. The proportion of CD20-positive patients in the standard-risk and high-risk groups was not significantly different $[15,16]$. Thus, about $20 \%$ and $10 \%$ of the patients with Ph-negative BCP-ALL in our study were CD20-negative and CD20-positive standardrisk, respectively. Our analysis suggests a favorable prognosis for CD20-negative standard-risk BCP-ALL patients, despite being treated with chemotherapy alone. Within the standard-risk patients, we found that CD20negative patients had a CR rate of $100 \%$ and better longterm outcomes compared with CD20-negative patients. With chemotherapy alone, the 3-year DFS and OS rates for these patients were $52.1 \%$ and $55.8 \%$, respectively. However, the dissatisfactory response and survival rates of the CD20-positive standard-risk patients did not differ from those of high-risk patients treated without alloHCT. This patient group may benefit from additional therapeutic modalities.

Allo-HCT is a standard treatment option for high-risk adult ALL patients [22, 23]. Our previous retrospective analysis showed superior survival of
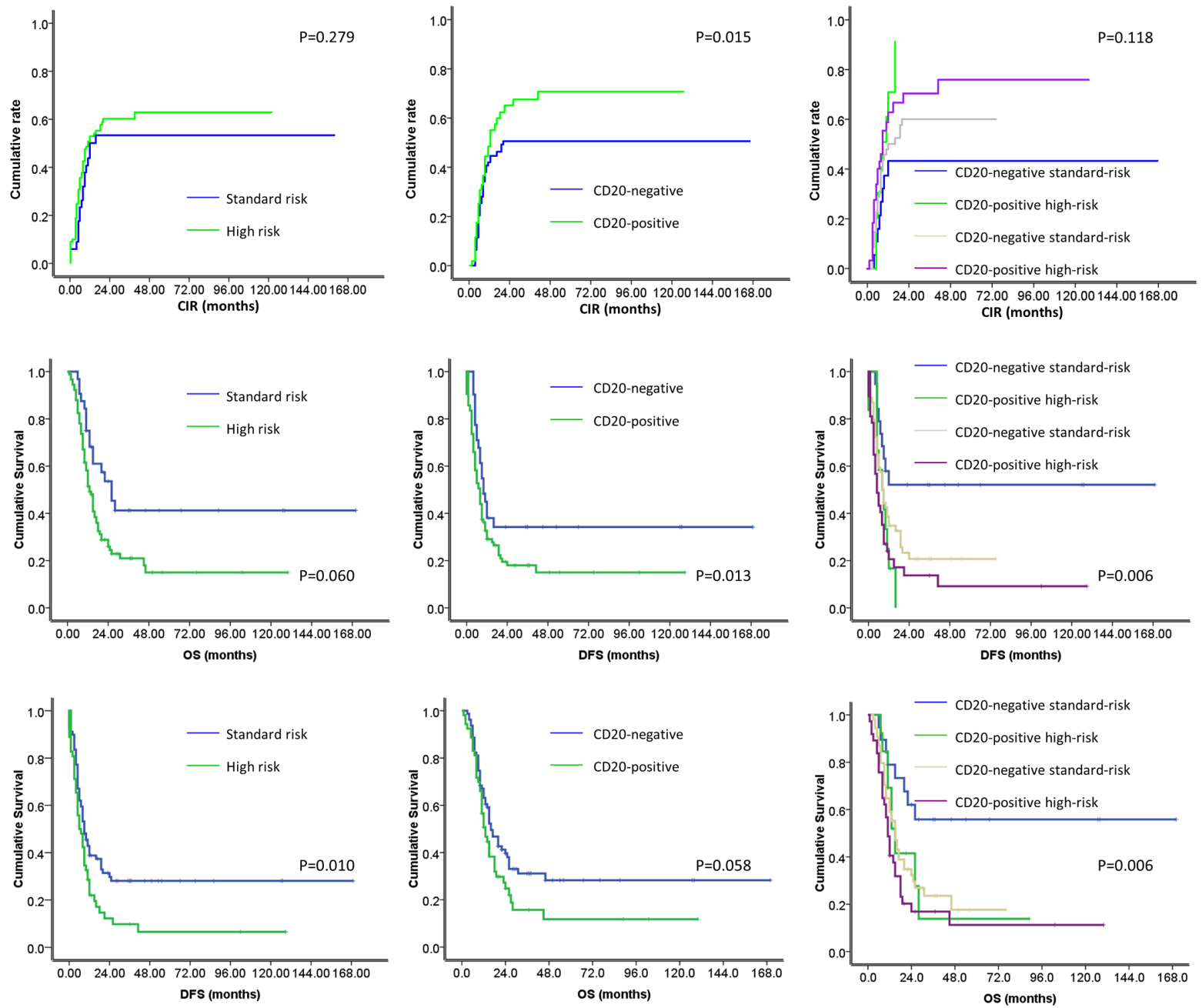

Figure 1: Survival according to risk status and CD20 expression: CD20-positive patients had higher 3-year cumulative incidence of relapse than CD20-negative patients $(73.1 \%$ vs. 54.7\%, respectively; $\mathrm{P}=0.015)$ and lower 3 -year disease free survial(12.2\% vs. 29.7\%, respectively; $P=0.013)$. 
Table 4: Univariate and multivariate analysis of risk factors for cumulative incidence of relapse, disease-free survival, and overall survival in patients treated with chemotherapy

\begin{tabular}{|c|c|c|c|c|c|c|c|c|c|c|c|c|}
\hline & \multicolumn{4}{|c|}{ 3-year CIR } & \multicolumn{4}{|c|}{ 3-year DFS } & \multicolumn{4}{|c|}{ 3-year OS } \\
\hline & \multicolumn{2}{|c|}{ Univariate analysis } & \multicolumn{2}{|c|}{ Multivariate analysis } & \multicolumn{2}{|c|}{ Univariate analysis } & \multicolumn{2}{|c|}{ Multivariate analysis } & \multicolumn{2}{|c|}{ Univariate analysis } & \multicolumn{2}{|c|}{ Multivariate analysis } \\
\hline & HR(95\%CI) & $P$ & HR(95\%CI) & $P$ & HR(95\%CI) & $P$ & HR(95\%CI) & $P$ & $\operatorname{HR}(95 \% \mathrm{CI})$ & $P$ & $\operatorname{HR}(95 \% \mathrm{CI})$ & $P$ \\
\hline High risk & $\begin{array}{c}1.462 \\
(0.833-2.567)\end{array}$ & 0.186 & $\begin{array}{c}1.255 \\
(0.687-2.292)\end{array}$ & 0.460 & $\begin{array}{c}1.610 \\
(0.981-2.644)\end{array}$ & 0.060 & $\begin{array}{c}1.581 \\
(0.961-2.603)\end{array}$ & 0.071 & $\begin{array}{c}2.018 \\
(1.184-3.439)\end{array}$ & $0.010^{*}$ & $\begin{array}{c}2.055 \\
(1.199-3.527)\end{array}$ & $0.009^{* *}$ \\
\hline \multicolumn{13}{|l|}{$\begin{array}{l}\text { Factors not included } \\
\text { in risk stratification }\end{array}$} \\
\hline Female & $\begin{array}{c}1.105 \\
(0.564-2.165)\end{array}$ & 0.612 & & & $\begin{array}{c}0.935 \\
(0.632-1.382)\end{array}$ & 0.735 & & & $\begin{array}{c}0.733 \\
(0.488-1.101)\end{array}$ & 0.135 & $\begin{array}{c}0.674 \\
(0.437-1.039)\end{array}$ & 0.074 \\
\hline $\mathrm{HB} \geq 100 \mathrm{~g} / \mathrm{L}$ & $\begin{array}{c}0.907 \\
(0.503-1.488)\end{array}$ & 0.700 & & & $\begin{array}{c}0.890 \\
(0.586-1.352)\end{array}$ & 0.585 & & & $\begin{array}{c}0.958 \\
(0.622-1.474)\end{array}$ & 0.844 & & \\
\hline $\mathrm{PLT} \geq 100 \times 10^{9} / \mathrm{L}$ & $\begin{array}{c}1.962 \\
(1.074-3.586)\end{array}$ & $0.028^{*}$ & $\begin{array}{c}1.773 \\
(0.903-3.482)\end{array}$ & 0.096 & $\begin{array}{c}1.668 \\
(1.019-2.730)\end{array}$ & $0.042^{*}$ & $\begin{array}{c}1.308 \\
(0.732-2.337)\end{array}$ & 0.364 & $\begin{array}{c}1 . .516 \\
(0.913-2.518)\end{array}$ & 0.108 & $\begin{array}{c}1.173 \\
(0.640-2.149)\end{array}$ & 0.605 \\
\hline $\begin{array}{l}\text { Lymphadeopathy } \\
\text { and } \\
\text { hepatosplenomegaly }\end{array}$ & $\begin{array}{c}1.120 \\
(0.686-1.827)\end{array}$ & 0.897 & & & $\begin{array}{c}1.180 \\
(0.782-1.779)\end{array}$ & 0.431 & & & $\begin{array}{c}1.264 \\
(0.826-1.934)\end{array}$ & 0.281 & & \\
\hline CD20-positive & $\begin{array}{c}1.773 \\
(1.116-2.817)\end{array}$ & $0.015^{*}$ & $\begin{array}{c}1.802 \\
(1.061-3.061)\end{array}$ & $0.029^{*}$ & $\begin{array}{c}1.648 \\
(1.110-2.445)\end{array}$ & $0.013^{*}$ & $\begin{array}{c}1.917 \\
(1.237-2.971)\end{array}$ & $0.004^{*}$ & $\begin{array}{c}1.485 \\
(0.987-2.235)\end{array}$ & 0.058 & $\begin{array}{c}1.484 \\
(0.965-2.282)\end{array}$ & 0.073 \\
\hline $\begin{array}{l}\text { Consolidation with } \\
\text { hyperCVAD }\end{array}$ & $\begin{array}{c}1.414 \\
(0.889-2.247\end{array}$ & 0.143 & $\begin{array}{c}1.574 \\
(0.945-2.622)\end{array}$ & 0.081 & $\begin{array}{c}1.308 \\
(0.882-1.939)\end{array}$ & 0.181 & $\begin{array}{c}1.463 \\
(0.946-2.261)\end{array}$ & 0.087 & $\begin{array}{c}0.991 \\
(0.685-1.492)\end{array}$ & 0.964 & & \\
\hline
\end{tabular}

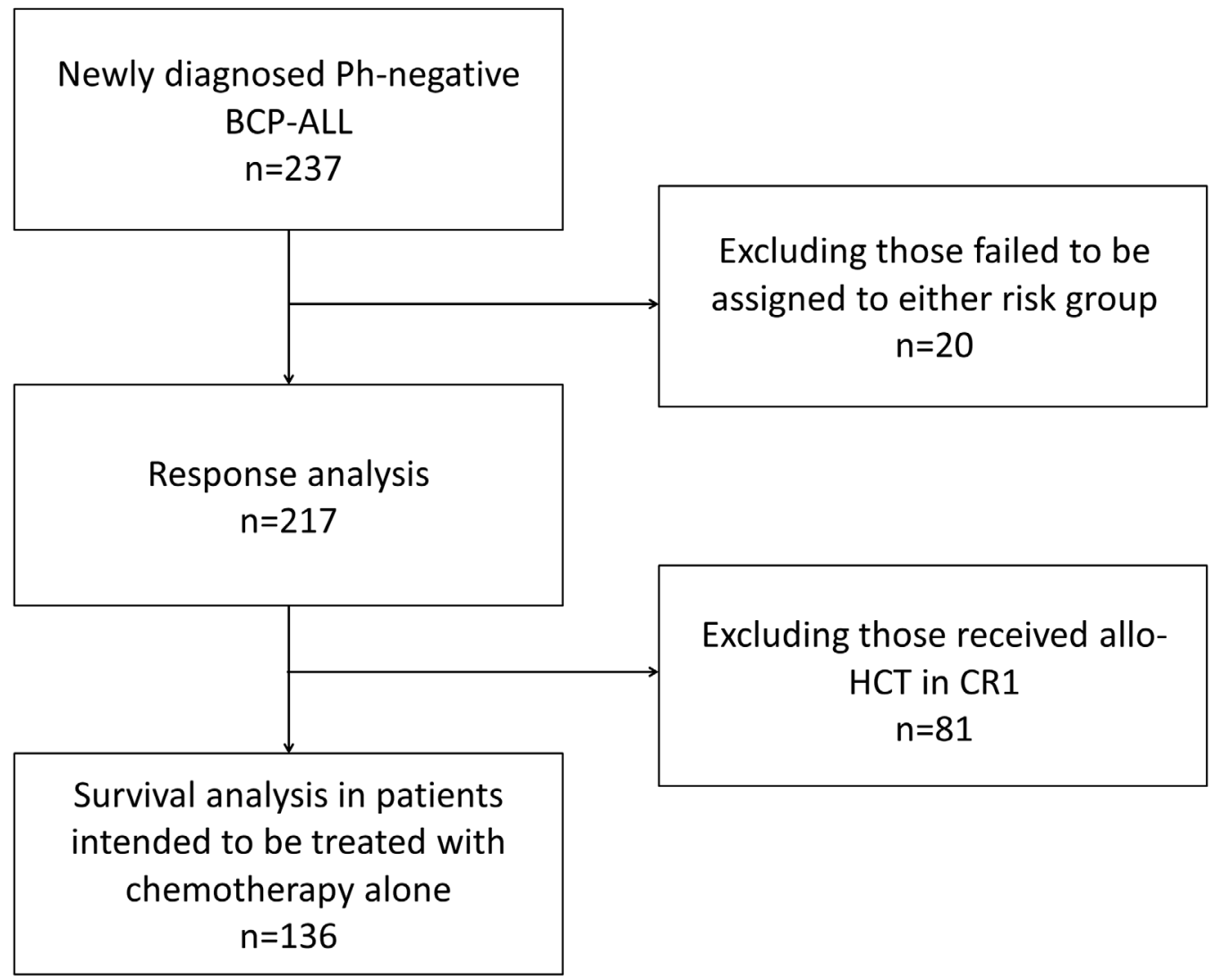

Figure 2: Study design: 237 consecutive patients aged $\geq 18$ and $<65$ years with a diagnosis of de novo $\mathrm{Ph}$-negative $\mathrm{BCP}$ ALL were included in the study. 217 patients could be assigned to standard-risk or high-risk groups were analyzed for responses to induction chemotherapies. 136 patients were intended to be treated with chemotherapy alone and were analyzed for long-term outcomes. 
Table 5: The cytogenetic and molecular genetic prognostic risk stratificationfor adult Philadelphia chromosomenegative $B$ cell precursor acute lymphoblastic leukemia $[5,33]$

Standard risk

Intermediate risk

High risk

Very high risk high hyperdiploidy with 51-65 chromosomes

normal, abnormalities of 11q (not MLL), del(6q), del(17p), del(12p), -13/ $\operatorname{del}(13 \mathrm{q}), \mathrm{t}(14 \mathrm{q} 32), \mathrm{t}(10 ; 14)$, low hyperdiploidy $(47-50)$, tetraploidy ( $>80$, no structural changes), all others

$-7, \operatorname{del}(7 \mathrm{p}),+8$, other 11q23/MLL translocations, $\mathrm{t}(1 ; 19)$ or $\mathrm{t}(17 ; 19)$

$\mathrm{t}(4 ; 11) / \mathrm{AF} 4 / \mathrm{MLL}+, \mathrm{t}(8 ; 14) / \mathrm{MYC} / \mathrm{IGH}+$, complex karyotype $(\geq 5$ abnormalities) with or without translocations, combined low hypodiploidy

(30-39)/near triploidy (60-78) patients receiving haploidentical allo-HCT at CR1, with a 3-year DFS of $\sim 70 \%$, independent of risk status [24, 25] Our preliminary analysis of 81 patients who received allo-HCT in CR1 in this cohort shows significant improved DFS and OS in all risk groups. We are working on the study to clarify the role of allo-HCT in patients with BCP-ALL. Patients with CD20-positive standardrisk ALL have a poor prognosis and are also supposed to benefit from allo-HCT. However, it should be noted that the lower rate of durable CR1 in patients with CD20positive ALL may cause difficulties in bringing patients to allo-HCT in CR1.

Studies from the MD Anderson Cancer Center and the randomized GRAALL-R 2005 study have demonstrated that survival rates of patients with CD20-positive ALL are higher when treated with a combination of rituximab and chemotherapy compared with chemotherapy alone [26-28]. The addition of L-asparaginase may also benefit CD20-positive patients [29]. With a minimal residual disease-adapted therapeutic strategy, CD20-positive ALL patients did not have poorer outcome than CD20-negative patients as demonstrated by the NILG-ALL 09/00 protocol [20]. All these studies suggest therapeutic options to alleviate the negative effect of CD20 expression in patients with ALL.

The major limitation of our study is retrospective nature. Therefore, further studies to compare chemotherapy and allo-HCT in CR1 for CD20-negative standard-risk patients are warranted. Moreover, it will be interesting to investigate whether rituximab can significantly improve the prognosis of patients with CD20positive standard-risk ALL. For the time being, our results suggest that $\mathrm{CD} 20$ expression adds to the known risk factors for Ph-negative BCP-ALL patients.

\section{MATERIALS AND METHODS}

\section{Study design and the patients}

We conducted a retrospective study to evaluate the significance of ALL cell CD20 expression within the traditional risk stratifications and to redefine standard- risk BCP-ALL. We enrolled 237 consecutive patients aged $\geq 18$ and $<65$ years with a diagnosis of de novo $\mathrm{Ph}$-negative BCP-ALL who were treated at Peking University Institute of Hematology from January 2000 to February 2015. Twenty patients could not be assigned to standard-risk or high-risk groups because of indeterminate karyotype and absence of other highrisk factors, and they were excluded from the analysis. Data from the final cohort of 217 patients were analyzed for responses to induction chemotherapies. Eightyone patients who achieved durable CR1 ( $\geq 3$ months) received allogeneic transplantation according to their choice and donor availability. The remaining 136 patients were intended to be treated with chemotherapy alone and were analyzed for long-term outcome (Figure 2). All patients provided informed consent for treatment under a protocol reviewed and approved by Peking University Institute of Hematology. The last follow-up was conducted in October 2015.

\section{Diagnosis}

Ph-negative BCP-ALL was diagnosed according to the WHO classification with morphologic, immunophenotypic, cytogenetic, and molecular analyses of bone marrow. Briefly, bone marrow smears were processed with Wright-Giemsa staining and viewed by experienced hematopathologists. We used 4-color and 8-color flow cytometry for leukemia diagnosis before and after 2009. PerCP-Cy5.5-conjugated anti-CD20 (Biolegend, San Diego, CA, USA) was used in 8-color flow cytometry and FITC conjugated anti-CD20 (BD, San Jose, CA, USA) in 4-color flow cytometry. CD20positivity was defined as expression of CD20 on $\geq 20 \%$ of leukemia blasts. The positivity of CD20 expression determined by both 8 -color and 4-color flow cytometry was comparable. Cytogenetic analysis was performed on bone marrow specimens after short-term $(24 \mathrm{~h})$ culture using the G-banding technique. Ph-negativity was confirmed by the absence of BCR-ABL fusion transcripts by TaqMan-based real-time (RT)-PCR and fluorescence in situ hybridization analysis. Expression of other leukemia- 
associated genes, such as MLL and E2A-PBX1, was also evaluated by TaqMan-based RT-PCR.

CNSL was diagnosed when the cerebrospinal fluid (CSF) leukocyte count was $\geq 5 \times 10^{6} / \mathrm{L}$ or when blasts were detected in cytocentrifuged CSF specimens. EMD was defined as pathologic or radiologic evidence of disease in organs or tissue other than the blood or bone marrow (e.g., CNS, soft tissue, testes, skin, liver, or spleen).

\section{Risk stratification}

Patients were evaluated according to the wellestablished risk factors of WBC count $\geq 30 \times 10^{9} / \mathrm{L}$ and age $\geq 35$ years old [30-32]. Patients were divided into four risk subgroups by cytogenetic and molecular abnormalities based on the MRC UKALLXII/ECOG E2993 adult ALL classification [5, 33] (Table 5). After modification according to the GRAALL trial [16], high-risk was defined as at least one of the following factors at baseline: age $\geq 35$ years, WBC $\geq 30 \times 10^{9} / \mathrm{L}, \mathrm{CNSL}$, and high- or very highrisk cytogenetic abnormality.

\section{Treatments}

All patients were administered $\mathrm{CODP} \pm \mathrm{L}$ as the induction regimen (cyclophosphamide $800 \mathrm{mg} / \mathrm{m}^{2}$ on day 1 ; vincristine $1.4 \mathrm{mg} / \mathrm{m}^{2}$ on days $1,8,15$, and 22; daunorubicin $45 \mathrm{mg} / \mathrm{m}^{2}$ on days $1-3$ and 15-17; prednisone $1 \mathrm{mg} / \mathrm{kg}$ on days $1-19$ followed by tapering to cessation on day 28; with or without L-asparaginase $6000 \mathrm{U} / \mathrm{m}^{2}$ on days 19-28). Different consolidation regimens were used before and after 2010. After 2010, two regimens were used: alternative modified hyperCVAD B (methotrexate $1 \mathrm{~g} / \mathrm{m}^{2}$ on day 1 and cytarabine $1-2 \mathrm{~g} / \mathrm{m}^{2}$ every $12 \mathrm{~h}$ on days $1-3$ ) or hyper-CVAD A (cyclophosphamide $300 \mathrm{mg} / \mathrm{m}^{2}$ every $12 \mathrm{~h}$ on days $1-3$; dexamethasone $40 \mathrm{mg} /$ day on days $1-4$ and 11-14; vincristine $1.4 \mathrm{mg} / \mathrm{m}^{2}$ on days 4 and 11; and doxorubicin $50 \mathrm{mg} / \mathrm{m}^{2}$ on day 4). Before 2010, three regimens were used: alternative $\mathrm{CODP} \pm \mathrm{L}$ (cyclophosphamide $750 \mathrm{mg} / \mathrm{m}^{2}$ on day 1 ; vincristine $1.4 \mathrm{mg} / \mathrm{m}^{2}$ on day 1 ; daunorubicin $45 \mathrm{mg} / \mathrm{m}^{2}$ on day 1 ; prednisone $1 \mathrm{mg} / \mathrm{kg}$ on days $1-7$; with or without l-asparaginase $6000 \mathrm{U} / \mathrm{m}^{2}$ on days 8-17), high dose methotrexate $\left(1-1.5 \mathrm{~g} / \mathrm{m}^{2}\right.$ on day 1$)$, or CAM (cyclophosphamide $800 \mathrm{mg} / \mathrm{m}^{2}$ on day 1; cytarabine 100/ $\mathrm{m}^{2}$ on days 1-7; and mercaptopurine $75 \mathrm{mg} / \mathrm{m}^{2}$ on days 1-7). Patients received consolidation chemotherapy for 6 to 8 cycles. Subsequently, they received maintenance therapy for 2 years consisting of a combination of 6-mercaptopurine $\left(75 \mathrm{mg} / \mathrm{m}^{2} /\right.$ day $)$, methotrexate $(20 \mathrm{mg}$ / $\mathrm{m}^{2} /$ week $)$, vincristine $\left(1.4 \mathrm{mg} / \mathrm{m}^{2} /\right.$ month, capped at 2 $\mathrm{mg}$ ), and prednisone (60 $\mathrm{mg} / \mathrm{m}^{2}$ on days $1-5$ monthly). CNSL prophylaxis consisted of intrathecal chemotherapy with methotrexate $10 \mathrm{mg}$, cytarabine $50 \mathrm{mg}$, and dexamethasone $5 \mathrm{mg}$ for at least 8 doses during induction and consolidation chemotherapy. Patients with active
CNSL were administered intrathecal chemotherapy twice a week until the CSF examination was negative, followed by a regular schedule of intrathecal injections. EMD (except CNSL) was treated with systemic chemotherapy. Rituximab was not included in the protocol.

Consenting patients with appropriate donors received allo-HCT during CR1. The outcomes of those patients are not discussed here.

\section{Response criteria and the outcome assessment}

CR was defined as (i) $\leq 5 \%$ blasts in normocellular marrow or hypercellular marrow with absolute neutrophil count $\geq 1 \times 10^{9} / \mathrm{L}$, (ii) platelets $\geq 100 \times 10^{9} / \mathrm{L}$, and (iii) resolution of EMD. CR duration $\geq 4$ weeks was required as CR criterion. Relapse was defined as reappearance of (i) blasts in the blood, (ii) $>5 \%$ blasts in bone marrow, or (iii) evidence of EMD following a CR. DFS was measured from CR until relapse or death. OS was measured from initiation of treatment until death.

\section{Statistical analysis}

Statistical analyses were performed using SPSS version 17.0 (IBM-SPSS, Chicago, IL, USA). Comparison of patient characteristics based on CD20 expression was performed with chi-square test. Responses of standardrisk vs high-risk patients (total and CD20 stratified) were compared with chi-square test. Potential risk factors were evaluated by univariate and multivariate analysis. Potential risk factors with $\mathrm{P}$ values $\leq 0.2$ in univariate analysis were entered into the multivariate analysis. DFS and OS were analyzed by Kaplan-Meier survival curves. Hazard ratios (HRs) for all variables were determined by Cox proportional hazard regression models. The Impact of risk factors on CIR was analyzed by a competing risk analysis using $\mathrm{R}$ project and the cmprsk package. All reported $\mathrm{P}$ values were two-sided. Statistical significance was set at $\mathrm{P}<0.05$.

\section{Author contributions}

SMY and QJ designed the study, analyzed the data, performed the statistical analysis, and provided clinical care to patients; TZ, JSJ, HHZ, HJ, JL, BJ, LPX, and XJH provided clinical care to patients; HXS performed the morphologic analysis; YRL performed the flow cytometric and molecular studies; and YYL performed the cytogenetic analysis. SMY and QJ wrote the paper with contributions from all coauthors.

\section{ACKNOWLEDGMENTS}

We thank Prof. Michael Andreeff (Section of Molecular Hematology and Therapy, Department of Leukemia, MD Anderson Cancer Center, Houston, 
Texas, USA), Prof. Hervé Tilly (Hospices Civils de Lyon, Université Claude Bernard, UMR CNRS5239, PierreBénite, France), and Prof. Won Seog Kim (Samsung Medical Center, Sungkyunkwan University School of Medicine, Seoul, South Korea) for their kind review of the manuscript and helpful comments.

\section{CONFLICTS OF INTEREST}

The authors declare that they have no conflicts of interest.

\section{FUNDING}

Natural Science Foundation of China (Grant No. 81200359).

\section{REFERENCES}

1. Thomas X, Boiron JM, Huguet F, Dombret H, Bradstock K, Vey N, Kovacsovics T, Delannoy A, Fegueux N, Fenaux P, Stamatoullas A, Vernant JP, Tournilhac O, et al. Outcome of treatment in adults with acute lymphoblastic leukemia: analysis of the LALA-94 trial. J Clin Oncol. 2004; 22:4075-4086.

2. Hoelzer D, Gokbuget N. New approaches to acute lymphoblastic leukemia in adults: where do we go? Semin Oncol. 2000; 27:540-559.

3. Hoelzer D, Thiel E, Loffler H, Buchner T, Ganser A, Heil G, Koch P, Freund M, Diedrich H, Ruhl H, Et A. Prognostic factors in a multicenter study for treatment of acute lymphoblastic leukemia in adults. Blood. 1988; 71:123-131.

4. Hunault M, Harousseau JL, Delain M, Truchan-Graczyk M, Cahn JY, Witz F, Lamy T, Pignon B, Jouet JP, Garidi R, Caillot D, Berthou C, Guyotat D, et al. Better outcome of adult acute lymphoblastic leukemia after early genoidentical allogeneic bone marrow transplantation (BMT) than after late high-dose therapy and autologous BMT: a GOELAMS trial. Blood. 2004; 104:3028-3037.

5. Moorman AV, Harrison CJ, Buck GA, Richards SM, SeckerWalker LM, Martineau M, Vance GH, Cherry AM, Higgins RR, Fielding AK, Foroni L, Paietta E, Tallman MS, et al. Karyotype is an independent prognostic factor in adult acute lymphoblastic leukemia (ALL): analysis of cytogenetic data from patients treated on the Medical Research Council (MRC) UKALLXII/Eastern Cooperative Oncology Group (ECOG) 2993 trial. Blood. 2007; 109:3189-3197.

6. Mancini M, Scappaticci D, Cimino G, Nanni M, Derme V, Elia L, Tafuri A, Vignetti M, Vitale A, Cuneo A, Castoldi G, Saglio G, Pane F, et al. A comprehensive genetic classification of adult acute lymphoblastic leukemia (ALL): analysis of the GIMEMA 0496 protocol. Blood. 2005; 105:3434-3441.
7. Lazarus HM. Central nervous system involvement in adult acute lymphoblastic leukemia at diagnosis: results from the international ALL trial MRC UKALL XII/ECOG E2993. Blood. 2006; 108:465-472.

8. Raff T, Gokbuget N, Luschen S, Reutzel R, Ritgen M, Irmer S, Bottcher S, Horst HA, Kneba M, Hoelzer D, Bruggemann M. Molecular relapse in adult standard-risk ALL patients detected by prospective MRD monitoring during and after maintenance treatment: data from the GMALL 06/99 and 07/03 trials. Blood. 2007; 109:910-915.

9. Szczepanski T. Why and how to quantify minimal residual disease in acute lymphoblastic leukemia? Leukemia. 2007; 21:622-626.

10. Kako S, Morita S, Sakamaki H, Ogawa H, Fukuda T, Takahashi S, Kanamori H, Onizuka M, Iwato K, Suzuki R, Atsuta Y, Kyo T, Sakura T, et al. A decision analysis of allogeneic hematopoietic stem cell transplantation in adult patients with Philadelphia chromosome-negative acute lymphoblastic leukemia in first remission who have an HLA-matched sibling donor. Leukemia. 2010; 25:259-265.

11. Gupta V, Richards S, Rowe J. Allogeneic, but not autologous, hematopoietic cell transplantation improves survival only among younger adults with acute lymphoblastic leukemia in first remission: an individual patient data meta-analysis. Blood. 2013; 121:339-350.

12. Goldstone AH, Richards SM, Lazarus HM, Tallman MS, Buck G, Fielding AK, Burnett AK, Chopra R, Wiernik PH, Foroni L, Paietta E, Litzow MR, Marks DI, et al. In adults with standard-risk acute lymphoblastic leukemia, the greatest benefit is achieved from a matched sibling allogeneic transplantation in first complete remission, and an autologous transplantation is less effective than conventional consolidation/maintenance chemotherapy in all patients: final results of the International ALL Trial (MRC UKALL XII/ECOG E2993). Blood. 2008; 111:1827-1833.

13. Oliansky DM, Larson RA, Weisdorf D, Dillon H, Ratko TA, Wall D, McCarthy PL, Hahn T. The role of cytotoxic therapy with hematopoietic stem cell transplantation in the treatment of adult acute lymphoblastic leukemia: update of the 2006 evidence-based review. Biol Blood Marrow Tr. 2012; 18:18-36.

14. Messori A, Fadda V, Maratea D, Trippoli S. Acute lymphoblastic leukemia in first complete remission: temporal trend of outcomes in studies comparing allogeneic transplant with autologous transplant or chemotherapy. Ann Hematol. 2013; 92:1221-1228.

15. Thomas DA, O'Brien S, Jorgensen JL, Cortes J, Faderl S, Garcia-Manero G, Verstovsek S, Koller C, Pierce S, Huh Y, Wierda W, Keating MJ, Kantarjian HM. Prognostic significance of CD20 expression in adults with de novo precursor B-lineage acute lymphoblastic leukemia. Blood. 2009; 113:6330-6337. 
16. Maury S, Huguet F, Leguay T, Lacombe F, Maynadie M, Girard S, de Labarthe A, Kuhlein E, Raffoux E, Thomas X, Chevallier P, Buzyn A, Delannoy A, et al. Adverse prognostic significance of CD20 expression in adults with Philadelphia chromosome-negative B-cell precursor acute lymphoblastic leukemia. Haematologica. 2010; 95:324-328.

17. Li H, Ayer LM, Lytton J, Deans JP. Store-operated cation entry mediated by CD20 in membrane rafts. J Biol Chem. 2003; 278:42427-42434

18. Kawabata KC, Ehata S, Komuro A, Takeuchi K, Miyazono K. TGF-beta-induced apoptosis of B-cell lymphoma Ramos cells through reduction of MS4A1/CD20. Oncogene. 2013; 32:2096-2106.

19. Bonavida B. Rituximab-induced inhibition of antiapoptotic cell survival pathways: implications in chemo immunoresistance, rituximab unresponsiveness, prognostic and novel therapeutic interventions. Oncogene. 2007; 26:3629-3636.

20. Mannelli F, Gianfaldoni G, Intermesoli T, Cattaneo C, Borlenghi E, Cortelazzo S, Cavattoni I, Pogliani EM, Fumagalli M, Angelucci E, Romani C, Ciceri F, Corti C, et al. CD20 expression has no prognostic role in Philadelphianegative B-precursor acute lymphoblastic leukemia: new insights from the molecular study of minimal residual disease. Haematologica. 2012; 97:568-571.

21. Chang H, Jiang A, Brandwein J. Prognostic relevance of CD20 in adult B-cell precursor acute lymphoblastic leukemia. Haematologics. 2010; 95:1040.

22. Yeoh AE, Tan D, Li C, Hori H, Tse E, Pui C. Management of adult and paediatric acute lymphoblastic leukaemia in Asia: resource-stratified guidelines from the Asian Oncology Summit 2013. Lancet Oncol. 2013; 14:e508-e523.

23. NCCN clinical practice guidelines in oncology: Acute Lymphoblastic Leukemia (Version 2. 2016). https://www. nccn.org/professionals/physician_gls/f_guidelines.asp.

24. Yan CH, Jiang Q, Wang J, Xu LP, Liu DH, Jiang H, Chen H, Zhang XH, Liu KY, Huang XJ. Superior survival of unmanipulated haploidentical HSCT compared with chemotherapy alone used as post-remission therapy in adult standard-risk acute lymphoblastic leukemia in first complete remission. Biol Blood Marrow Tr. 2014; 20:1314-1321.

25. Mo XD, Xu LP, Zhang XH, Liu DH, Wang Y, Chen H, Yan CH, Chen YH, Han W, Wang FR, Wang JZ, Liu KY, Huang XJ. Haploidentical hematopoietic stem cell transplantation in adults with Philadelphia-negative acute lymphoblastic leukemia: no difference in the high- and low-risk groups. Int J Cancer. 2014; 136:1697-1707.

26. Maury S, Chevret S, Thomas X, Heim D, Leguay T, Huguet F, Chevallier P, Hunault M, Boissel N, Escoffre-Barbe M, Hess U, Vey N, Braun T, et al. Addition of rituximab improves the outcome of adult patients with CD20-positive, $\mathrm{Ph}$-negative, B-cell precursor acute lymphoblastic leukemia (BCP-ALL): results of the randomized GRAALL-R 2005 study. Blood. 2015; 126:1.

27. Maury S, Chevret S, Thomas X, Heim D, Leguay T, Huguet FO, Chevallier P, Hunault M, Boissel N, Escoffre-Barbe M, Hess U, Vey N, Pignon J, et al. Rituximab in B-lineage adult acute lymphoblastic leukemia. N Engl J Med. 2016; 375:1044-1053.

28. Thomas DA, O'Brien S, Faderl S, Garcia-Manero G, Ferrajoli A, Wierda W, Ravandi F, Verstovsek S, Jorgensen JL, Bueso-Ramos C, Andreeff M, Pierce S, Garris R, et al. Chemoimmunotherapy with a modified hyper-CVAD and rituximab regimen improves outcome in de novo Philadelphia chromosome-negative precursor B-lineage acute lymphoblastic leukemia. J Clin Oncol. 2010; 28:3880-3889.

29. Maury S, Huguet F, Ifrah N, Dombret H, Béné M; The Group Research on Adult Acute Lymphoblastic Leukemia. L-asparaginase for adult CD20 positive B-cell precursor acute lymphoblastic leukemia. Haematologica. 2010; 95:1042.

30. Rowe JM. Induction therapy for adults with acute lymphoblastic leukemia: results of more than 1500 patients from the international ALL trial: MRC UKALL XII/ECOG E2993. Blood. 2005; 106:3760-3767.

31. Rowe JM. Prognostic factors in adult acute lymphoblastic leukaemia. Brit J Haematol. 2010; 150:389-405.

32. Le QH, Thomas X, Ecochard R, Iwaz J, Lhéritier V, Michallet M, Fiere D. Proportion of long-term event-free survivors and lifetime of adult patients not cured after a standard acute lymphoblastic leukemia therapeutic program: adult acute lymphoblastic leukemia-94 trial. Cancer. 2007; 109:2058-2067.

33. Pullarkat V, Slovak ML, Kopecky KJ, Forman SJ, Appelbaum FR. Impact of cytogenetics on the outcome of adult acute lymphoblastic leukemia: results of Southwest Oncology Group 9400 study. Blood. 2008; 111:2563-2572. 